$\square$ Forestry for Development - Proceedings of the Annual Forestry Symposium 1995, Sri Lanka, 1516 December 1995. (Eds. Amarasekera, H S and Banyard, S G). Published by Department of Forestry and Environmental Science, University of Sri Jayewardenepura, Sri Lanka (1996)

\title{
SPATIAL DATA AWARENESS AND COORDINATION THE PREREQUISITES FOR LAND RESOURCES MANAGEMENT
}

\author{
N. C. Seneviratne \\ Sri Lanka Survey Department
}

\begin{abstract}
Land is man's most valuable resource, It has to be properly managed If optimum benefit is to be reaped from it for an ever increasing population. Increasing population creates a varied demand on land use which cannot be addressed by a single agency - it thus becomes the responsibility of several different agencies. These agencies cannot each take decisions in a vacuum but should be able to assess the impact of therr decisions on each other. Use of spatial data enables one to do just that. Spatial data is information related to any location in the real world. Information in a spatial format enables one to understand the interaction of things in their spatial relationships - which is just what is required in land resources management. However, not many planners use spatial data in their decision making for reasons discussed in this paper. Acquisition of spatial data is a time consuning, exacting and an expensive process. Hence there is a great need for coordination of efforts in the collection of spatial data.

This paper discusses what spatial data is avallable for land resources management, how it can be used for the sustainable development of land resources and the advancement in technology that is helping to better manage our land resources:
\end{abstract}

\section{WHAT IS SPATIAL DATA ?}

Spatial data is information related to any location in the real world. The most important example of spatial data is the printed map. Other forms of spatial data are data acquired by remote sensing techniques. Examples of these are aerial photographs and satellite data. They need more complex methods of interpretation before they could be used as "information" or converted to map form. However, rectified aerial photographs and orthophotos could be used directly for many land resources related activity.

The great advantage of spatial data is that it enables one to understand the interaction of things in their spatial relationship, which is not evident in other data formats such 
Seneviratne

A word of advise to users of spatial data, especially maps, is that the scale of the map, the date of the primary information used and accuracy have to studied carefully before use. This aspect is dealt with fully in Seneviratne (1995).

\section{WHAT DATA ARE USEFUL ?}

Until recently, most development programs dealt with only economic issues and there are abundant statistical data sets which deal with "GNP per capita". The addition of environmental and social issues to the equation to support the goals of sustainable human development greatly increases the need for additional information in spatial format.

In our concern for sustainable human development the data sets that would be useful are those that help the decision makers to analyze "problems" related to:-

\begin{tabular}{ll} 
- & Resource consumption and depletion \\
- & Wasteful and polluting production patterns \\
- & Increasing population \\
- & Poverty \\
- & Soil degradation \\
- & Fresh water \\
- & Biodiversity \\
\hline & Disasters
\end{tabular}

It is evident that most of these problems are direct concerns of the Forestry Sector in the management of Forest Resources. They were considered when drawing up the National Forestry Policy (NFP). The Forestry Sector Master Plan (FSMP) which is to convert the NFP and its development strategies to action plans have proposed, among other things, a whole list of items which involve the collection of spatial data. Among the proposals are:-

- $\quad$ Mapping of individual natural forests.

- Much of the unmanaged and extensively managed land, such as open land in the dry zone are to be converted either to home gardens, other agroforestry systems or forest plantations. These lands have first to be identified and mapped.

- Institutional support in the form of improved land security/tenure. These have to be surveyed and defined.

- $\quad$ Mapping of state land suitable for home gardens.

- Opening suitable state land for leasing for tree growing. These have to be identified and surveyed.

- Land best suited for plantation forests will be placed under efficient management. These have first to be identified.

- Zoning and mapping forest plantations.

Much of the data required is already available and an initial study of what is available has to be made and thereafter strategies developed to fill the missing gaps. 
3 WHAT DATA IS AVAILABLE?

The Sri Lanka Survey Department (SD) has been the prime producer of spatial data which is made available to users in the form of plans, maps, aerial photographs, satellite imagery, and published schedules. The following are available in the SD:-

- $\quad$ A large number of cadastral maps at large scales in the District Survey offices (DSOs). These include Forests and Forest Reserves (where surveyed) and other state and private lands. Inquiries have to be made at the respective DSOs.

- Topographic Maps at the scale of one inch to a mile covering the entire country (72 map sheets). New maps are being published at the scale of 1:50,000 (92 sheets $90 \%$ completed) and 1:10,000 on request. Forests and forest plantations are shown on these maps.

- $\quad$ Land Use Maps at the scale of 1:100,000 for all Districts.

- $\quad$ Many thematic maps including soils, forest cover, etc.

- $\quad$ Aerial Photography at different scales from 1:20,000 to 1:50,000. Contact prints, enlargements, rectified photos and orthophotos can be obtained on order. With proper photo-interpretation some of the areas needed above such as open land, natural forests, and in particular deforestation and degraded forests can be identified.

- Satellite imagery is available from both with the SD and the Forest Department (FD).

There are other sources of original spatial data such as the Land Use Division of the Irrigation Dept. (Soil Data), Land Use Policy Planning Division of the Ministry of Agriculture, Lands and Forestry (Land Use Indicative maps).

\section{COORDINATION}

Acquisition of spatial data is an exacting, time consuming and an expensive process. Duplication of effort in its collection should be avoided wherever possible. Furthermore, much of the spatial data requirements are common to many agencies. Therefore, those agencies responsible for its collection should make it available to users without much hassle. Also, agencies requiring the same set of data should agree on standards such as accuracy, categorization etc. to facilitate collection.

Unfortunately, the SD experience is that spatial data that is produced at great cost is not put to optimum use. There are several reasons for this, namely, some users are unaware of its existence; some are unable to purchase it because of restrictions such as security or the producers are not willing to part with it; some potential users do not know how to use it.

There needs to be a greater coordination: firstly among the producers of data, to divide responsibility in order to avoid duplication of effort in the collection of data, 
Seneviratne

needs of users - for example the data may not be available in the format (scale, accuracy and date of information acquisition) required by the users. There has also to more education and training in the use of spatial data.

6

WHAT NEW TECHNOLOGY HAS TO OFFER

There are two very important developments that have taken place in the last decade. First is a tool called Geographical Information Systems (GIS), which will help in the analysis of some of the problems listed above such as identifying the land best suited for plantation forests, etc. The other is a tool called Global Positioning Systems (GPS), to determine the coordinates and height of any position on the earth such as a boundary of a forest, without using standard survey procedures which are time consuming.

GIS is a computer based tool for collecting, storing, retrieving at will, transforming, analyzing and displaying spatial data from the real world (geographic data) for a particular set of purposes. Geographic data describes objects from the real world in terms of:

a) their position with respect to a known system of coordinates, eg. a point feature such as a tree by a single set of coordinates, a line feature such as a road by a string of point coordinates joined one to another, an area feature such as a forest patch as a polygon which is a series of lines closing on itself

b) their attributes unrelated to their position, such as the description of a tree, the classification of a road or the description of a stand of trees

c) their spatial interrelationships (topology) which describes how they are linked together. Unlike in a map where the different features are shown all together, in a GIS the road network, hydrology, contours, soil classification, land use, etc. are stored separately. This is akin to taking a tracing of that feature only from a topographical sheet. These layers can be called at will separately for purposes of analysis.

In a GIS, the most expensive component is the collection of data to form the data bases. Even greater coordination among GIS users is required.

GPS systems are priced according to their accuracy. Whereas systems with greater accuracy are needed for establishing geodetic control, less precise systems could be used for topographical mapping and the determination of boundaries at medium and smaller scales. The SD is in possession of both categories. Here again, coordination is necessary in purchasing a system as Sri Lanka, being a poor country, should learn to share resources - especially hi-tech resources.

\section{REFERENCES}

Seneviratne, N.C. (1995). The use of spatial data in decision making. (Presidential addrace Cantion $C$ CI $\triangle \Delta C$ I 